\title{
Analgesic Prescriptions Patern Following Abdominal Surgery in A University Teaching Hospital
}

\author{
Article by Akanbi O. O. ${ }^{1}$, Habeeb O. G. ${ }^{2}$, Adeoti L. M. ${ }^{3}$, Idris O. L $^{4}$, Adejumobi M. O. ${ }^{5}$, \\ Olaogun J. O. ${ }^{6}$, Akinloye T. A. (MBBS) ${ }^{7}$ \\ ${ }^{1}$ Ladoke Akintola University of Technology Teaching Hospital, Ogbomoso, Oyo State \\ Nigeria \\ ${ }^{2}$ University of Ilorin and University of Ilorin Teaching hospital, Ilorin Kwara State Nigeria \\ ${ }^{3}$ Ladoke Akintola University of Technology Teaching Hospital, Ogbomoso, Oyo State \\ Nigeria \\ ${ }^{4}$ Ladoke Akintola University of Technology Teaching Hospital, Osogbo, Osun State \\ Nigeria \\ ${ }^{5}$ Ladoke Akintola University of Technology Teaching Hospital, Osogbo, Osun State \\ Nigeria \\ ${ }^{6}$ Surgery department Ekiti State University, Ado-Ekiti, Ekiti State \\ ${ }^{7}$ Ladoke Akintola University of Technology Teaching Hospital \\ Ogbomoso, Oyo State Nigeria \\ E-mail:drsolaakanbi@yahoo.com ${ }^{1}$,drhabeebog@yahoo.com ${ }^{2}$,adeoti7449@yahoo.com ${ }^{3}$, \\ idrisol@yahoo.com ${ }^{4}$,adejumobi43@gmail.com ${ }^{5}$,olaogunjulius@yahoo.com ${ }^{6}$, \\ akinloye_taiwo@yahoo.com ${ }^{7}$
}

\begin{abstract}
Background: Pain is an inevitable occurrence following surgery and its control is an important component of post-operative care. Many patients still suffer from poor post-operative pain control which is associated with a lot of secondary undesirable consequences.

Methods: We conducted a prospective observational study on 120 patients undergoing abdominal surgery over a 3-year period in a teaching hospital to determine adequacy and pattern of analgesic prescriptions. The patients' case notes were retrieved from the record unit of the hospital following discharge and relevant data extracted.

Results: The mean age of the patients was 47.36 ( \pm 8.933$)$. Twenty-four (20\%) were older than 65 years. The most common abdominal surgical procedure performed was appendectomy. Non-steroidal anti-inflammatory drugs only, opiod only, opiod-NSAID combination and NSAID-NSAID combinations were prescribed for $42.5 \%, 30.83 \%, 14.16 \%$ ) and $7.85 \%$ of cases respectively and no prescription in $3.3 \%$ of cases. Pentazocine was the most commonly prescribed opiod. Females tend to have more opiod prescriptions than males $(O R=3.4, p=0.0052)$. Other factors that favoured opiod prescription include; age $<65$ years $(O R=4.8571, p=.0019)$, patient in high social class $(O R=$ 3.6364, $p=0.4182)$, and Yoruba ethnicity $(O R=3.2406, p=0.0149)$. Non-steroidal analgesics were the most commonly prescribed analgesic to patients that underwent major abdominal surgeries.

Conclusion: We thus recommend use of analgesic combinations and dose adjustment based on patients' severity of pain in post-operative abdominal pain control.
\end{abstract}

Keywords: Pattern, Analgesic prescription, Abdominal surgery and Postoperative pain.

\section{Introduction}

Pain is an inevitable occurrence following surgery and its control is an important component of post-operative care that has received much attention, [Kehler 2004, White \& Kehler 2010] Though not all pain requires drug treatment however analgesic is the main stay of post-operative pain management. This acute form of pain is secondary to direct tissue injury and obligate nociceptive inflammatory mediators resulting from damage to vascularised tissues. Many patients still suffer from poor post-operative pain control. [Mark \& Sachar, 1973; Cohen, 1980; Kuhn, 1990] This form of pain is controllable when appropriate mode of analgesia is chosen, and with use of recent analgesia 
techniques. [AHCPR, 1992; Torda, 1995; McQuay, et al 1997] Poor post-operative abdominal pain control is associated with a lot of secondary undesirable consequences [Bruster ,1994; McQuay, et al 1997] that may affect interpretation of patients' physiological parameters as well as increased risk of certain post-operative complications following abdominal surgeries such as pulmonary complications, deep venous thrombosis and psychosocial and economic adverse effects among others. [Heyburn, 2003; White \& Kehler, 2010; Apfelbaum, et al 2003] It also one of the major causes of delayed recovery of normal bowel function, and prolonged hospital stay. [Rowbotham, 1993; Heyburn, 2003] Various factors such as opiphobia, disparity in pattern of opiod prescriptions are responsible for poor post-operative pain control. Opiphobia resulting from fear of "drug-seeking" behaviour, dependence or addiction and respiratory depression has been identified in various clinical setting. This opiphobic phenomenon has resulted in a situation in which adequate analgesia is difficult to achieve in many clinical conditions. In lieu of present documented evidences for poor post-operative pain control and its effects, surgeons need to be well equipped and versed in pain management especially in an acute setting. The aim of this study was to investigate the extent of opiphobia and other factors that are responsible for disparity in opiod analgesic prescription and administration pattern among patients that underwent abdominal surgery in our centre.

\section{Methods}

This prospective observational study consecutively recruited 120 patients that are undergoing abdominal surgery between May 2014 and May 2017 in Ladoke Akintola University of Technology Teaching Hospital Ogbomoso. Patients admitted to intensive care unit following abdominal surgery were excluded from the study. The patients' case notes were reviewed while on admission and after discharged to obtain other relevant data. The data obtained from the patients' case notes included: Socio demographic characteristics of the patients, clinical diagnosis, definitive surgical procedures patients underwent, analgesic prescribed for the patients, analgesic patients received, drug(s) patients were discharged on. All this were done without the knowledge of all other members of the general surgery units and other surgical unit staffs that were involved in patients' care to avoid bias in their analgesic prescriptions. The data obtained were analysed using Biostatistics for Ipad (Apple inc. USA) and Microsoft Office Excel version 2007. The data were presented in forms of tables and charts. Chi-square was used as test of significance for categorical variable and $P$ value less than .05 was considered to be statistical significance.

\section{Results}

One hundred and twenty patients were targeted for the study. The mean age of the patients was 47.36 ( \pm 8.933$)$. Twenty-four $(20 \%)$ out of the 120 patients were older than 65 years. The sociodemographic characteristics of the patients were as shown in table 1.

The most common abdominal surgical procedure performed over the study period was appendectomy which constituted $31.66 \%$ of the total procedures; other procedures were inguinal hernia repair, small bowel surgery, cholecystectomy (with or without billiary duct exploration), colonic surgery and gastroduodenal surgery. (Figure 1)

Fifty-eight $(48.33 \%)$ cases were emergencies while $62(57.40 \%)$ cases were elective. Nonsteroidal anti-inflammatory drugs (NSAID) were the most commonly prescribed agents and was sole prescription in $51(42.5 \%)$ patients while opiod analgesic only, opiod-NSAID and NSAID/NSAID combination were prescribed in $37(30.83 \%), 17(14.16 \%)$ and $11(7.85 \%)$ of the cases respectively with no evidence of prescription in $4(3.3 \%)$ cases. Eighty-two (56.9\%) out of 144 number of prescriptions were in generic names.

Analysis of opiod analgesic prescriptions revealed that pentazocine was the most commonly prescribed opiod (Figure 2). Review and analysis of pentazocine prescriptions revealed that in twentysix $(83.87 \%)$ out of the thirty-one prescriptions, it was prescribed at a dosage of 30mg 6 hourly.

Twenty-three $(31.08 \%)$ out of seventy-four males had opiod prescription as part of their analgesic prescriptions as compared to thirty-one (67.39\%) females out of 46 females who had opiod as part of their prescribed analgesic. This pattern of differential analgesic prescription between males and females shows statistically significant difference $(\mathrm{OR}=3.4, P=.0052)$. 
Sixty-four $(69.8 \%)$ out of ninety-six patients who were less than 65 years ha opiod analgesic as part of their analgesic prescriptions as compared to seven (29.16\%) out of twenty-four patients older than sixty-five years $(\mathrm{OR}=4.8571, \mathrm{p}=.0019)$. Figure 3 shows variation in opiod prescriptions across different age groups.

When opiod prescriptions were compared among different ethnic groups Yoruba patients ha higher frequency of opiod prescriptions as compared to other ethnic groups as sixty-one (69.89\%) out of 93 Yoruba patients, 5 (27.27\%) out of 11 Igbo patients, and 5 out (18.75\%) of 16 Hausa/Fulani had opiod prescription as part of their analgesic prescription ( $\mathrm{OR}=3.2406, P=0.0149)$.

Five $(83.33 \%)$ patients belonging to high social class ha opiod analgesic in their prescriptions as compared to $66(57.9 \%)$ out of 114 patients in low and intermediate social classes. This pattern of opiod analgesic prescriptions shows a statistically significant difference among the social classes $(\mathrm{OR}=3.6364, \mathrm{p}=0.4182)$.

Analysis of NSAID prescriptions revealed that diclofenac was the most commonly prescribed NSAID. (Figure 4).

Eighty-seven $(72.5 \%)$ of the patients were discharged home without evidence of analgesic prescription and in none of the case notes were documented evidence of patients' pain score assessment while in wards and prior to discharge. Most documented evidence of take home analgesic prescription were seen mainly in patients who had elective hernia repairs as seventeen out of the 21 patients who had elective hernia repair were discharged home on same day with five, two, four, one and three patients on paracetamol only, diclofenac only, diclofenac-ibuprofen combination, meloxicam- paracetamol combination and dihydrocoidine-diclofenac combination respectively.

\section{Discussion}

Analgesics are often prescribed in the postoperative period to control postoperative pain following all forms of surgery. Control of post-operative abdominal pain is very important in post-operative setting to avoid unwanted effects of oligoanalgesia such as deranged physiological parameters, restlessness, and poor patients' cooperation among others.

Our study found out that non-steroidal anti-inflammatory drugs were the most commonly prescribed analgesic following abdominal surgery. Further analysis of NSAID prescription revealed that NSAID-NSAID were wrongly combined in about $9 \%$ of prescriptions a finding consistent with another study that reported similar pattern of prescription. [Sinan, 2012] This NSAID- NSAID combination is not advisable, however if such occasion should arise due to severity of the pain the rational alternative will be NSAID in combination with other class of analgesic such as opiod or paracetamol which has little adverse effects on the gastro intestinal mucosa.[Becker \& Phero, 2005; Becker, 2010] About 57\% of the prescriptions were in generic names a finding comparable to what is found in a study on analysis of prescriptions in a teaching hospital. [Raftery, et al 1995] The acts of prescription in brand names is to be discouraged as this will leave the patients to insist on a particular brand of drug that may not even be available when generic alternatives are available and possibly at a lower cost.

Pentazocine was the most commonly prescribed opiod analgesic (figure 2). Possible explanations for infrequent prescriptions of stronger opiod analgesic include unavailability and high cost of morphine and other more potent opiod analgesic agents such as fentanyl, pethidine. The pentazocine, which is the most commonly prescribed opiod analgesic was prescribed in about $84 \%$ of occasions at a dosage of 30mg every 6 hours for a drug whose half-life is between 3 to 4 hours; irrespective of the patients' age, weight and severity of pain. Though no statistically significant difference in pattern of opiod prescriptions for males and females, however female are three times more likely to receive opiod analgesic as compared to male. This preferential pattern of stronger analgesic agents for females was previously reported in a study. [Raftery, et al 1995] The possible explanation for this sex preferential prescription in favour of female could be due to observation that females tend to be more sensitive to pain but less responsive to analgesic. A similar study on analgesic prescription between male and female patients revealed that female patients were more likely to show less tolerance to pain than males and thus were perceived by the clinicians to be in more pain than the male patients for similar conditions and thus received higher dosage and more potent analgesic. [Raftery, et al 1995] 
This preferential pattern of analgesic prescription pattern was also observed among the younger age groups as patients who are less than 65 years were two times more likely to have opiod prescription in their analgesic prescriptions a finding consistent with Jones JS and co-workers' study finding, which showed that older age group were more prone and at risk of oligoanalgesia for various reasons. [Jones, 1996].

The opiod prescription pattern was in favour of Yoruba ethnic group as opiod prescription was much higher in Yoruba ethnic group as compared to other ethnic groups. The role of ethnicity as one of the major factors contributing to opiod and other analgesic disparity prescriptions pattern has been documented in some studies. [Todd, 1993; Todd, 2000] The preference for opiod analgesic prescriptions for Yoruba ethnic group was probably borne out of non-documented and perceived popular socio-cultural belief among Nigerians that Hausa/Fulani and Igbo tend to be stronger and can withstand pain much better. Though the effects of cultural bias on pain tolerance, cultural differences between patients and the prescriber may also contribute to this bias on analgesic prescriptions. [Todd, 1993; Todd 2000] Other factor identified to favour opiod prescription was patients' social class as patients in high social class received more opiod prescriptions compared to patients in lower and middle social classes. The possible explanation for this could be better purchasing power of patients in high social class and perceived belief that high social class individual tends to be less tolerant to pain.

More than half of the patients who were admitted were discharged home without analgesic prescription as part of take-home drugs however all were given antibiotics in various forms and combinations. This habit of discharging patients' home without analgesic cannot be objectively justified as patients' pain severity were not assessed prior to discharge and thus we cannot assume that patients are pain free at the point of discharge.

Abdominal surgeries are associated with significant pain especially when upper abdomen is involved in the surgical incision. In spite of this recognition control of post-operative pain still remains a major challenge in post-operative setting. [Apfelbaum, 2003; White, 2008; White \& Kehler ,2010] Pain associated with abdominal surgeries often predisposes patients to shallow breathing with suppression of deep breathing in an effort to minimize pain thus making abdominal surgeries a risk factor for post-operative pulmonary complications (PPC) with reported incidence ranging from 5\% to 40\%. [Seiler, 2009; Hemmes, et al 2014].

Though the choice of post-operative pain control is affected by many factors such as availability of drugs and equipment in delivering the analgesic agents a reflection from our study, which shows that morphine constituted only about $2 \%$ of opiod prescriptions and possible explanation for this could be due to the cost and unavailability of the drug, a factor not alien to the authors. Also, none of the patients under study received analgesic in-form of patients control analgesia or epidural analgesia as form of post-operative analgesia, this was due to relative unavailability of the equipment for such modality in our setting a factor not uncommon in developing nations. Lack of stronger opiod analgesic agents is still an on-going challenge in many developing nations where opiod consumption and availability is reduced as once reported by World Health Organization (WHO) in 2003 that only $6 \%$ of world opiod are in developing nations where over $80 \%$ of world population are. [WHO, 2003] This skewed pattern of opiod distribution in favour of developed nations was also confirmed by International Narcotics Control Board 2010 report. [International Narcotics Control Board, 2001] Despite our limited resources, the authors believed that recognition of our deficiencies through routine assessment of our analgesic practices and sincerity of efforts are important factors that can help improve and assist in management post-operative abdominal pain. This is in support of Rawal's resolution who believed that solution to poor and inadequate post-operative pain control lie in optimal utilisation of our limited resources rather than procurement of expensive drugs, equipment and use of novel modalities [Acute pain services revisited, 2002] through a multimodal approach as previously suggested. [Rawal, 2001; Kehler, 2007; Macintyre \& Schug, 2007; Buvanendran \& Kroin, 2009; White \& Kehler, 2010]. 


\section{Conclusion}

Post-operative abdominal pain control still remains suboptimal as revealed from our study due to lack of understanding of analgesic use coupled with opiphobia and unavailability of stronger opiod analgesic agents. Non-steroidal analgesic agents were the most commonly prescribed analgesic to patients that underwent major abdominal surgeries. We recommend use of analgesic combinations and dose adjustment based on patients' severity of pain, in post-operative abdominal pain control.

\section{References}

[1]. Acute pain services revisited: Good from far, far from good? Reg Anesth Pain Med. 2002;117-121.

[2]. Agency for Health Care Policy and Research. Acute pain management: operative or medical procedures and trauma, part 1. Clin Pharm. 1992; 11:309-331.

[3]. Apfelbaum JL, Chen C, Mehta SS, Gan TJ. Postoperative pain experience: results from a national survey suggest postoperative pain continues to be under managed. Anesthy Analg. 2003; 97:534-540.

[4]. Becker DE. Pain management: Part 1: managing acute and postoperative dental pain. Anesth Prog 2010; 57:67-79.

[5]. Becker DE, Phero JC. Drug therapy in dental practice: nonopiod and opiod analgesic. Anesth Prog. 2005; 52:140-149.

[6]. Bruster S, Jarman B, Bosanquet N, Weston D, Erens R, Delbanco TL. National survey of hospital patients. Br Med J. 1994; 309: 1542-1546.

[7]. Buvanendran A, Kroin JS. Multimodal analgesia for controlling acute postoperative pain. Curr Opin Anaesthsiol. 2009; 22:588-593.

[8]. Cohen FL. Post surgical pain relief: patients' status and nurses' medication choices. Pain 1980; 9:265-274.

[9]. Hemmes SN, Gama de Abreu M, Pelosi P, Schultz MJ, PROVE Network Investigators for the Clinical Trial Network of the European Society of Anaesthesiology. High versus low positive end-expiratory pressure during general anaesthesia for open abdominal surgery (PROVHILO trial): a multicentre randomised controlled trial. Lancet. 2014; 384(9942):495-503.

[10]. Heyburn G. Pain management in elderly hip fracture patient. 2002. Retrieved from the World Wide Web 02 October $2003 \mathrm{http}: / /$ www.gerimed.

[11]. International Narcotics Control Board. Report of the International Narcotics Control Boardon the availability of international controlled drugs: Ensuring adequate Access for Medical and Scientific Purpose. New York, NY: International Narcotics Control Board; 2011.

[12]. Jones JS, Johnson K, McNinch M. Age as a risk factor for inadequate emergency department analgesia. Am J Emerg Med. 1996; 14:157-160.

[13]. Kehler H, Wilkison RC, Fischer HB, Camu F. Prospect working group. PROSPECT: Evidence-based, procedure-specific postoperative pain management, Best Pract Res Clin Anaesthsiol. 2007; 21:149-159.

[14]. Kehler PF. Effect of postoperative pain treatment on outcome-current status and future strategies. Lagenbecks. Arch Surg. 2004; 389:244-249.

[15]. Kuhn S, Cooker K, Collins M, Mucklow JC. Perc eption of pain rrelief after surgery. Br Med J. 1990; 300:1687-1690.

[16]. Macintyre PE, Schug SA, acute pain management. $3^{\text {rd }}$ ed. Edinburgh: Saunders Elsevier; 2007.

[17]. Mark RM, Sachar EJ. Undertreament oof medical inpatients with narcotic analgesic. Ann Intern Med. 1973; 76:173-181.

[18]. McQuay H, Moore A, Justin D. Treating acute pain in hospital. Br Med J. 1997; 314:1531-1535.

[19]. Raftery KA, Smith-Coggins R, Chen AH. Gender- associated differences in emergency department pain management. Ann Emerg Med.1995; 26:414-421.

[20]. Rawal N. Analgesiafor day case surgery. Br J Anaesth. 2001; 87:73-87.

[21]. Rowbotham D. Postoperative pain. Prescriber's J 1993; 33:237-243.

[22]. Seiler CM, Deckert A, Diener MK, Knaebel HP, Weigand MA, Victor N, et al. Midline versus transverse incision in major abdominal surgery: a randomized, double-blind equivalence trial (POVATI: ISRCTN60734227). Ann Surg. 2009; 249(6):913-20.

[23]. Sinan Sermet, Muserref Asuman Akgun, Sukran Atamer-Simsek. Analgesic prescription pattern in the management of dental pain among dentist in Istanbul. Marmara Pharmaceutical Journal. 2012; 16:41-47. DOI:10.12991/201216419. 
DOI: 10.21522/TIJMD.2013.07.01.Art004

ISSN: $2520-3118$

[24]. Todd KH, Deaton C, D'Adamo AP, et al. Ethnicity and analgesic practice [comments]. Ann Emerg Med, 2000; 35(1):11-6.

[25]. Todd KH, Samaroo N, Hoffman JR. Ethnicity as a risk factor for inadequate emergency department analgesia [comments]. JAMA, 1993. 269(12):1537-9.

[26]. Torda T. Postoperative analgesia. Aust Prescriber. 1995; 18:88-91.

[27]. White PF and Kehler H. Improving postoperative pain management: what are the unresolved issues? Anesthesiology. 2010; 112:220-225.

[28]. White PF. Pain management after ambulatory surgery- where is the disconnect? Can J Anaesth. 2008; 55:201-207.

[29]. World Health Organization. The World Health Report 2003. Geneva: WHO. 2003; Available from: http://www.who.int/whr/2003/en/overview /en.pdf.

Table 1. Showing sociodemographic characteristics of the patients

\begin{tabular}{|l|l|}
\hline Patients' parameters & Results \\
\hline Age: Range (mean SD) & $(47.36 \pm 8.933)$. \\
\hline Sex:(Male: Female) & $69: 51$ \\
\hline Ethnic Group & \\
Yoruba & 93 \\
Igbo & 11 \\
Hausa/Fulani & 16 \\
\hline Social class & \\
Low & 51 \\
Intermediate & 63 \\
High & 6 \\
\hline
\end{tabular}

\section{Legend of figures}

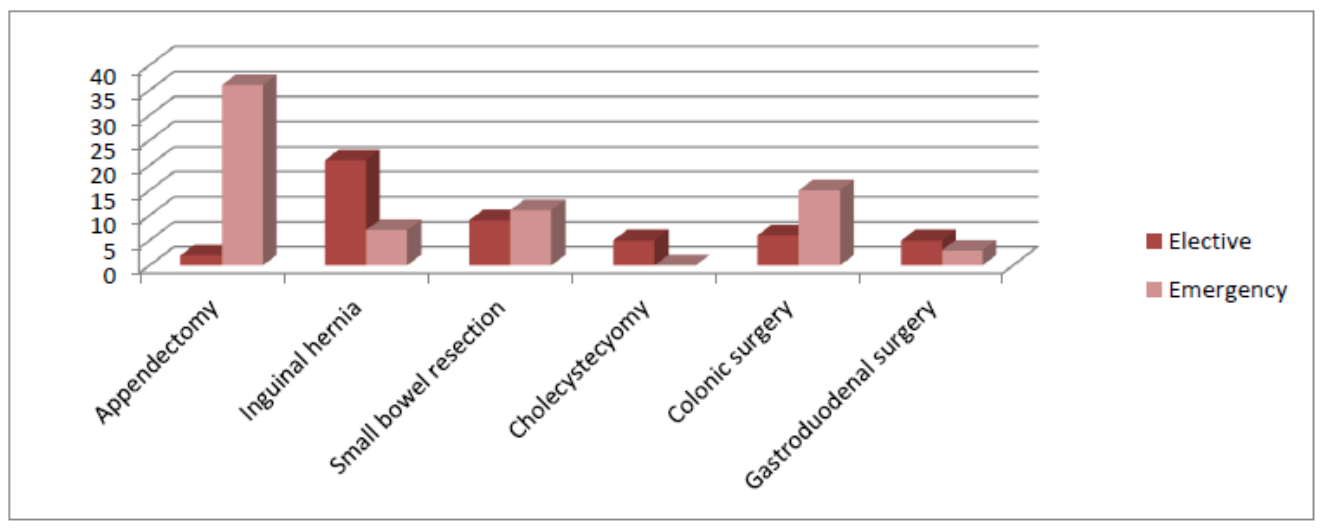

Figure 1. Showing spectrum of the operative procedures performed

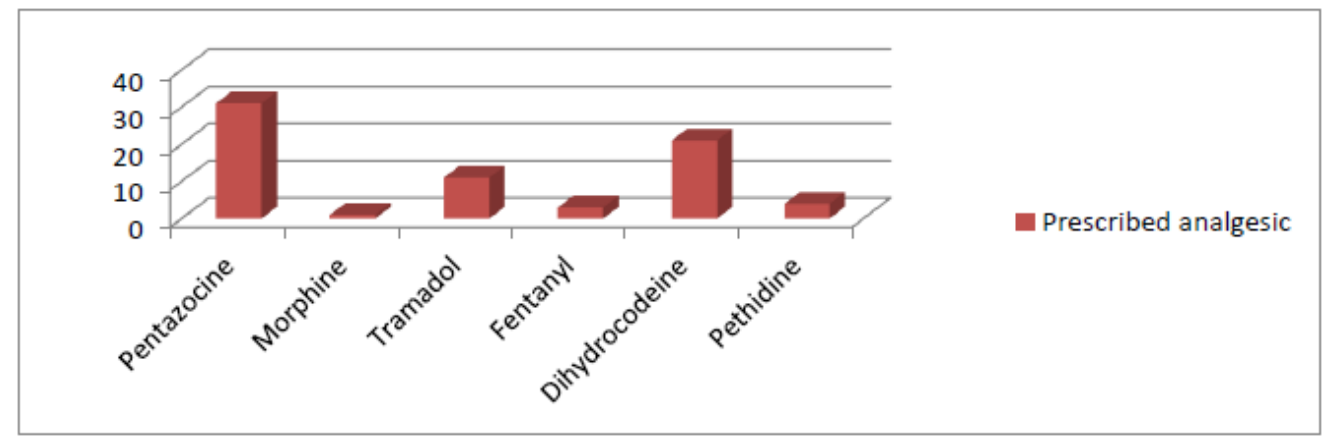

Figure 2. Pattern of Opiod prescriptions 
Texila International Journal of Medicine

Volume 7, Issue 1, Apr 2019

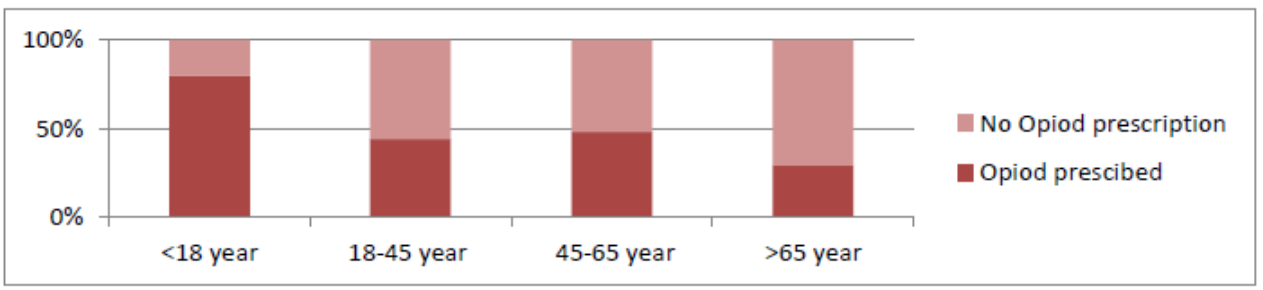

Figure 3. Showing differential pattern of opiod prescription across different age groups

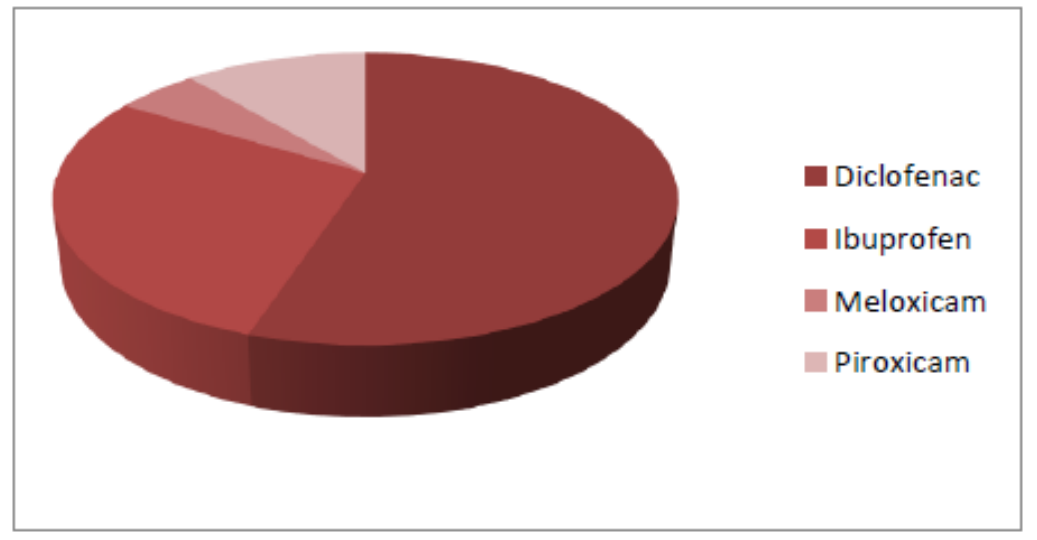

Figure 4. Showing pattern of NSAID prescriptions 